\title{
A Ciberarte no Reconhecimento dos Estados de Ânimo em Ambientes Virtuais de Aprendizagem
}

\author{
Magalí Teresinha Longhi \\ Patricia Alejandra Behar \\ Maria Crisitina Biazus \\ Programa de Pós-Graduação em Informática na Educação \\ Universidade Federal do Rio Grande do Sul (UFRGS) \\ Caixa Postal 5071 - 90.041-970 - Porto Alegre - RS - Brasil \\ mlonghi@cesup.ufrgs.br, pbehar@terra.com.br, cbiazus@ufrgs.br
}

Resumo: Este trabalho aborda uma revisão das teorias relacionadas à Ciberarte e à Endoestética, como também das tecnologias digitais aplicadas à Educação. São apresentadas estratégias voltadas à identificação dos estados de ânimo refletidos nos desenhos concebidos por crianças em ferramentas disponibilizadas no ambiente virtual de aprendizagem Planeta ROODA. Pretende-se evidenciar a influência da Ciberarte na construção de conhecimento quando da utilização de interfaces gráficas em sistemas informáticos para a aprendizagem. O projeto Empathic Painting desenvolvido nos departamentos de Ciência da Computação das universidades de Bath (Inglaterra) e Boston (EUA) serviu de base para as idéias apresentadas neste trabalho.

Palavras-chave: Estado de ânimo, Ambientes Virtuais de Aprendizagem, Ciberarte, Endostética.

\section{Thinking Cyberart to Mood Recogniton in Virtual Learning Environment}

Abstract: This work makes a review of the Cyberart and Endoesthetic theories and some digital technologies applied to Education. In this context, we show some strategies to identify mood in the children's drawings produced on tools of Planeta ROODA virtual learning environment. We have been intended to show the Cyberart influences of graphical interfaces in knowledge construction. The Empathic Painting project of Computer Science Departments at Bath (England) and Boston (USA) universities is basis to the ideas of this proposal.

Key-words: Mood, Virtual Learning Environment, Cyberart, Endoesthetic.

\section{Introdução}

As tecnologias digitais vêm sendo apresentadas como um paradigma transformador nas formas de pensar e raciocinar, das relações sociais, assim como, na produção, na aquisição e na construção de conhecimento. A ciência e a cultura, antes dissociadas, agora compõem a era pós-biológica onde a inserção das tecnologias cria extensões do corpo e sentidos humanos. 
A cibercultura ${ }^{1}$ faz vivenciar um virtual tecnológico em que não há mais fronteiras entre os mundos. $\mathrm{O}$ ciberespaço marca mais um espaço de interação humana de importância econômica e científica alcançando várias áreas como a Pedagogia, Estética, Arte e Política (Lévy, 2000). O espaço cibernético é um lugar poroso e rizomático (Lemos, 1996) de disseminação da cultura cibernética ${ }^{2}$.

A arte é dependente do momento histórico e, na era digital, contempla-se a Ciberarte $^{3}$ ou a arte cibernética como reconstruindo a ponte de união entre ciência, tecnologia e arte (Giannetti, 2006) tendo como característica principal a interatividade. Segundo Lemos (1997), a interatividade é uma nova forma de interação técnica, de característica eletrônico-digital constituindo uma ação dialógica entre homem e técnica. Já Primo (2003; p.130) entende que a interatividade "tornou-se por demais ligada às reações automatizadas do computador" e que o melhor termo a ser empregado seria interação mediada por, pois "a interação pode variar de acordo com a relação mantida entre os envolvidos, variando progressivamente da interação mais reativa (programada e determinística) à de maior envolvimento e reciprocidade, a interação mútua”.

A interatividade é característica essencial em sistemas virtuais para o ensinoaprendizagem. Behar et alli (2005) consideram um ambiente virtual de aprendizagem (AVA) constituído por uma infra-estrutura tecnológica (interface gráfica, comunicação síncrona/assíncrona e outras funcionalidades) e por todas as relações (afetivas, cognitivas, simbólicas, entre outras) estabelecidas pelos sujeitos participantes, tendo como foco principal a aprendizagem.

Este trabalho aborda a Ciberarte e a estética digital a fim de apresentar estratégias que identifiquem os estados de ânimo dos alunos do ensino fundamental por meio de desenhos realizados através da funcionalidade Planeta Arte do AVA Planeta ROODA $^{4}$.

Na próxima seção, apresenta-se uma revisão histórica da Ciberarte e são tecidas considerações sobre estética digital. Na Seção 3, são abordadas as tecnologias digitais e apresentado o Planeta ROODA, ambiente virtual de aprendizagem voltado à Educação Infantil e ao Ensino Fundamental. Na Seção 4, são feitas considerações genéricas sobre o estudo da afetividade e cognição e suas relações com a aprendizagem; enquanto que na Seção 5, é relatado o estado-da-arte do uso de tecnologias digitais para o

\footnotetext{
${ }^{1}$ Cyber (originário de cybernetics) + cultura pode ser entendida como uma forma sociocultural que advém de uma relação de trocas entre a sociedade, a cultura e as novas tecnologias digitais principalmente pela convergência das telecomunicações com a informática (Lemos, 2003).

2 O termo Cibernética foi introduzido por Norbert Weiner em 1948 para designar a teoria do controle e da comunicação nos seres vivos, nos grupos sociais e na máquina. Ciências interdiciplinares, da Filosofia à Neurociência, ajudaram a fundar a cibernética que se dispõe a modelar matematicamente os processos de tratamento da informação.

${ }^{3}$ Outros termos são utilizados como sinônimos de Ciberarte: arte eletrônica, arte tecnológica, media art, web.art, net.art, arte digital, arte na rede, arteônica, arte interativa ou arte telemática. Entretanto, alguns termos são de definição ampla. Efeitos especiais gerados por computador em filmes cinematográficos ou desenhos animados são obras digitais, mas não incorporam características da ciberarte como, por exemplo, a interatividade.
}

${ }^{4}$ Ambiente virtual de aprendizagem desenvolvido no NUTED (Núcleo de Tecnologia Digital Aplicada à Educação) vinculado à FACED/UFRGS (Faculdade de Educação) e ao CINTED/UFRGS (Centro Interdisciplinar de Novas Tecnologias na Educação). Disponível em http://www.nuted.edu.ufrgs.br/planeta. 
reconhecimento de emoções e é apresentada uma proposta para identificação dos estados de ânimo das crianças ao utilizarem tecnologias digitais para desenho. Finalmente, na Seção 6, são feitas algumas considerações sobre o assunto abordado.

\section{Ciberarte e Estética Digital}

$\mathrm{Na}$ década de 50, $\operatorname{artistas}^{5}$ influenciados pela cibernética começaram a criar obras de artes, instalações, baseados em sistemas eletrônicos e outras tecnologias, que podiam, algumas vezes, se modificar com a interação do espectador. Nesse momento surgem também as primeiras obras geradas por computador (Computer Art ${ }^{6}$ ) que pretendiam ser "sistemas abertos e funcionar como tal, possibilitando a conexão entre meio, artista e obra, entre obra e público, ou entre obra e contexto" (Giannetti, 2006, p.52).

Desde então, a expansão do uso da tecnologia como ferramenta da arte "colocou em evidência uma profunda e progressiva cisão entre a experiência artística, a crítica de arte e a estética" (Giannetti, 2006, p. 14). Segundo o Dicionário do Pensamento Social do Século XX (Outhwaite \& Bottomore, 1996), a estética é compreendida como uma disciplina filosófica que congrega a filosofia dos fenômenos estéticos (objetos, qualidade, experiências e valores), a filosofia da arte (da criatividade, da obra de arte e de sua percepção) e a filosofia da crítica (informação descritiva e/ou avaliativa).

Muitos críticos afirmam que a estética, no seu formato tradicional, possui métodos antiquados e baseados em princípios metodológicos inadequados (Outhwaite \& Bottomore, 1996). Fenômenos culturais de massa (por exemplo, música funk) e manifestações de vanguarda nas artes (por exemplo, instalações) não estão podendo ser suportados pela estética tradicional. $\mathrm{O}$ mesmo se verifica em relação à Ciberarte.

As tecnologias digitais não podem ser mais evitadas. A matéria, o tempo e o espaço não são mais os mesmos e as artes não podem mais ser entendidas como em outros tempos. As obras são definidas como sistemas complexos, multidisciplinares, hipermidiáticos, interativos. Giannetti (2006) estuda esta nova arte e, a partir das teorias da endofísica, desenvolve uma estética digital - a Endoestética. Esta é empregada para definir um modelo teórico que entenda e analise as possibilidades criativas oferecidas pelos novos recursos tecnológicos interativos. "A análise endoestética é adequada para discorrer sobre os mais diversos tipos de arte interativa, em que o público faz parte do sistema que observa com o qual interage e cujas ferramentas digitais são entendidas como artefatos inerentes ao endossistema e aos seus próprios processos." (Giannetti, 2006; p. 192).

Domingues (2004, p. 190) é bastante enfática: “o paradigma da representação, a idéia do belo, a contemplação das imagens ou de um objeto estão mudados pelas relações de corpos e computadores, entre corpos e redes, no contato de todos os corpos conectados entre eles, amplificados em dimensões planetárias, entre mentes e softwares. A arte interativa não é uma arte da representação com os materiais, nem uma arte de mídias. A ciberarte explora o comportamento dos sistemas artificiais, provocados pelos

\footnotetext{
${ }^{5}$ O húngaro Nicolas Schöffer, o coreano Naum June Paik e o britânico Gustav Metzger.

${ }^{6}$ Waldemar Cordeiro, entre 1969 e 1973, foi pioneiro na Computer Art no Brasil
} 
corpos humanos, exigindo um engajamento total com o que está sendo experimentado, através das respostas dos sistemas. Pressupõe um estado de implicação e atenção, interrogando-se sobre o modo de existir como uma possibilidade de estar reinventando constantemente a vida."

Os meios e as técnicas provocam mudanças na percepção humana, afetam a maneira de conhecer o mundo, de como representar e transmitir esse conhecimento (Lévy, 1997). Assim, as tecnologias digitais facilitam novas formas de pensar, de questionar valores, de produzir, reproduzir e propagar conhecimento e de estabelecer inter-relações. Todos estes temas se entrelaçam e perpassam pela afetividade. Perceber aspectos afetivos, nos projetos de artes em sala de aula mediados por tecnologias digitais, transforma a relação professor-aluno como também os processos de transmissão e apreensão do conhecimento.

\section{A Afetividade, os Estados de Ânimo e as Tecnologias Digitais}

Até o início do século XX, os movimentos filosóficos impulsionaram os debates sobre pensamento, conhecimento, comportamento, razão e emoção. A partir de então, com o estabecimento das grandes teorias psicológicas, a afetividade nas atividades cognitivas passou a ser reconhecida.

Piaget (1962), Vygotski (2001a) e Wallon (1971) contribuiram para desmitificar a dicotomia entre afetividade e cognição destacando que a afetividade, manifestada através da linguagem e interações sociais, é o agente motivador das atividades cognitiva. Por outro lado, os neurocientistas Damásio (1996) e Le Doux (2005) demonstram que os sistemas cerebrais destinados à afetividade apresentam-se intrinsecamente ligados aos sistemas destinados à cognição. Já outros pesquisadores das ciências cognitivas (Ortony et alli,1988; Roseman et alli, 1990; Izard, 1993; Scherer, 2005) concordam que crenças, desejos e intenções exercem influências sobre os processos cognitivos, os quais, por sua vez, ativam dimensões afetivas no sujeito (e vice-versa).

A afetividade pode ser conceituada como todo o domínio das emoções, dos sentimentos das emoções, das experiências sensíveis e, principalmente, da capacidade de entrar em contato com as sensações (Bercht, 2001). Os fenômenos afetivos, que fazem parte da afetividade, têm papel importante no comportamento inteligente, na tomada de decisão, na comunicação social, processos estes que supõem habilidades racionais.

Os estados de ânimo ${ }^{7}$, dentre os fenômenos que constituem a afetividade - que abrange também as emoções, os sentimentos, a motivação, etc. -, são caracterizados como estados globais, difusos, de longa duração e constantes. A partir desta definição, Scherer (2005) classifica os estados de ânimo em estar: 1) animado (no sentido de estar disposto, satisfeito, esperançoso, alegre, entusiasmado); 2) desanimado (estar triste, abatido, deprimido, pessimista, desgostoso, melancólico); 3) indiferente (desatento); 4) ansioso (preocupado, aflito); e 5) irritado (impaciente). Sendo assim, os estados de ânimo estão interligados com a motivação e a criatividade.

\footnotetext{
${ }^{7}$ Neste trabalho, usa-se o termo estado de ânimo como sendo o estado de humor baseado na disposição do espírito do sujeito.
} 
Para Paulo Freire, a motivação, em vez de preceder a ação, se processa ao longo da mesma (Freire e Schor, 1987). Isto é, a motivação associa-se à ação (aprender). Conclui-se, então, que se o estado de ânimo não estiver ajustado ao da ação, a motivação não será capaz de estabelecer vínculos com a criatividade e o conteúdo de aprendizagem.

O uso das tecnologias digitais abriu caminho para novos questionamentos em diversas áreas sobre a cognição, a afetividade e motivação na aprendizagem e, por conseqüência, o repensar de práticas pedagógicas. A linguagem das artes visuais no computador pode ampliar as possibilidades de uma experiência estética integrando as representações do mundo, as percepções, a sensibilidade, a criatividade e $\mathrm{o}$ conhecimento.

Com o desenvolvimento das tecnologias digitais de comunicação (blogs, chats, fóruns, $\mathrm{p} 2 \mathrm{p}$, tecnologias móveis, etc.), da computação gráfica, da realidade virtual, da visão computacional, e, recentemente, da computação afetiva, a Ciberate passa a ser o processo da desconstrução, virtualização e desmaterialização do mundo que vivemos. Só acontece com a participação do espectador, que não mais se comporta apenas como tal, mas também como um agente ativo, ou seja, como co-autor da obra. O espectador é "chamado a intervir diretamente na atualização (a materialização, a exibição, a edição, o desenrolar efetivo aqui e agora) de uma sequiência de signos ou de acontecimentos." (Lévy, 1999; p. 135). McLuhan (1974) acredita que uma nova tecnologia modifica (ou amplifica) os sentidos humanos, desencadeando mutações sensoriais e intelectuais, provocando muitas vezes grandes transformações estéticas.

\section{O Planeta Arte}

Biazus (2000) discute questões relacionadas com a imagem, o sujeito-criativo, a produção imagética e a diversidade disponibilizada em ambientes informatizados para a aprendizagem em arte na educação infantil. A autora observa que a interatividade potencializa a construção de um campo virtual de possibilidades que são próprias do sujeito podendo ser exteriorizadas através da simulação. Por sua vez, as obras de arte representam um possível para a criança.

Essa construção de um campo virtual de possibilidades é concebida pelo uso de interfaces ${ }^{8}$ multimídicas. As interfaces representam o limiar de espaços (entre o real e o virtual) definindo o meio de interação entre o homem e a máquina e favorecendo modos para a experimentação, a percepção e o emocionar. São elas que sustentam a interatividade que "proporciona ao interator a sensação de expansão de seu universo cognitivo e de suas capacidades sensório-motoras" (Giannetti, 2006; p.123).

As interfaces multimídicas são a base para os ambientes virtuais de aprendizagem que começam a fazer parte do cotidiano das escolas. Um exemplo é o Planeta ROODA destinado ao trabalho coletivo com crianças e professores, centrado no usuário e ambientado no espaço sideral. Tem como pressupostos o suporte ao trabalho

\footnotetext{
8 “O termo interface é oriundo primeiramente da física, onde significa simplesmente a superfície de contato entre duas fases, isto é, dois líquidos de características físico-químicas diferentes e que não se misturam. Neste contexto, a interface é derivada da impossibilidade de contaminação entre duas substâncias, ainda que temporária. Uma interface deste tipo é apenas um limite comum, como um contato que transfere forças de uma fase a outra e se move ou muda de formato pelo movimento das fases. Para a física, ela não é como um aparelho individualizado, mas faz parte da interação entre essas duas fases, traçando, por sua movimentação, um desenho, uma espécie de impressão ou, se quisermos, uma representação móvel das tensões entre elas." (Boechat, 2004; p. 17).
} 
coletivo e à lógica de pensamento das crianças, remetendo à possibilidade de interação entre os participantes e ao crescimento cognitivo dos mesmos, a fim de atender as peculiaridades deste período do desenvolvimento humano. A base teórica que fundamenta o ambiente baseou-se na teoria de Piaget, na qual o conhecimento é construído a partir das interações do sujeito com o meio físico e social (Behar et alli, 2006).

Uma das funcionalidades do Planeta ROODA é o Planeta Arte 9 (Figura 1) onde as crianças podem construir sua arte, montar e expor imagens, com a possibilidade de que outras crianças possam comentar suas produções.

A funcionalidade apresenta as ferramentas mais comuns aos softwares de edição de desenho como: lápis, giz de cera, borracha, figuras geométricas e texto. Destaca-se os carimbos, figuras pré-definidas no ambiente ou de criação do próprio aluno que podem ser utilizadas para enriquecer o desenho (Figura 2). Tão logo o desenho é gravado, o mesmo fica disponível na Galeria do Planeta Arte para ser visualizado e comentado por outros, como também ser transformado em "fundo de tela" para ser usado como imagem de fundo da tela do computador.

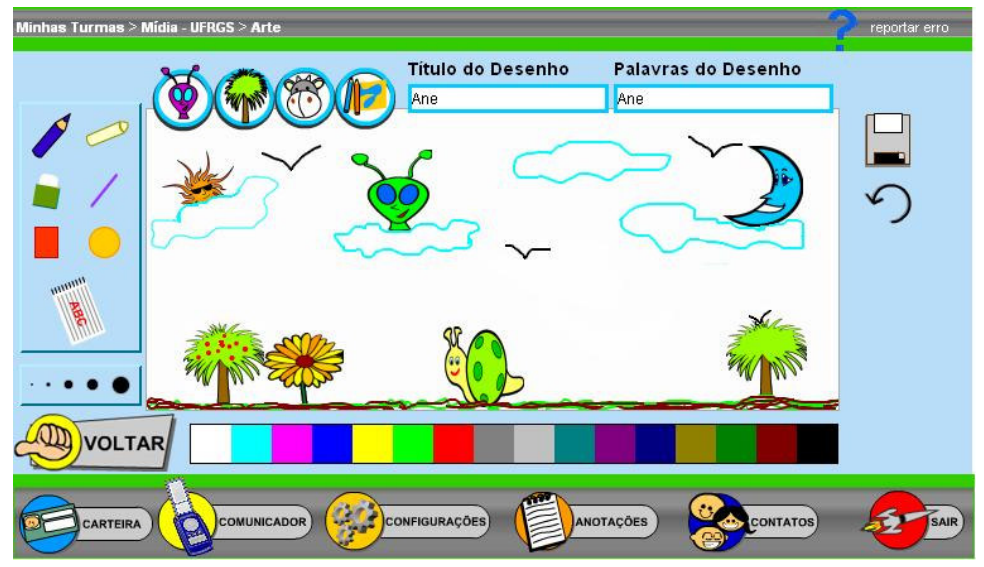

Figura 1: O editor de desenhos do Planeta Arte, funcionalidade do Planeta ROODA

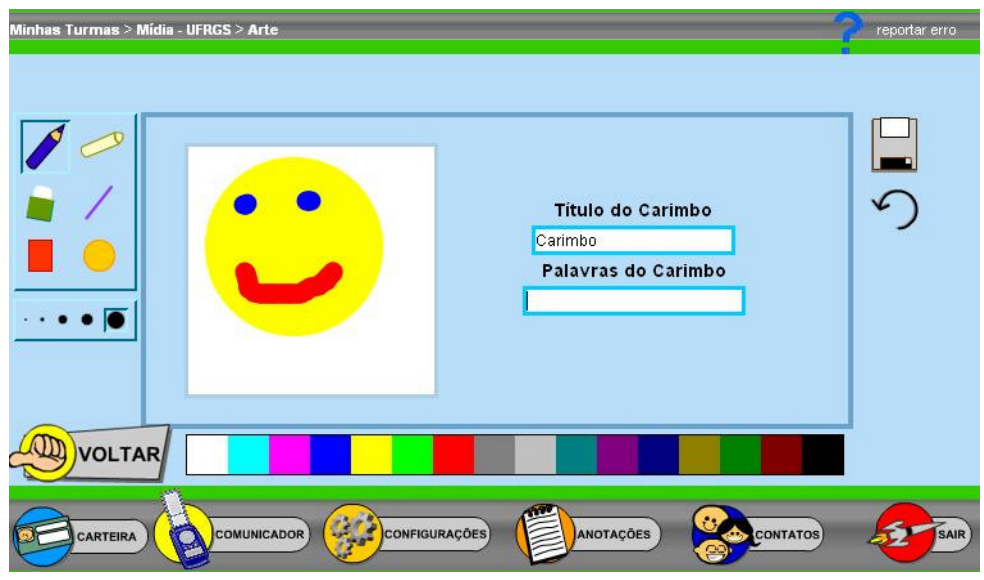

Figura 2: Novo carimbo criado pelo aluno

\footnotetext{
${ }^{9}$ O Planeta Arte foi desenvolvido em PHP e Ajax com banco de dados MySQL.
} 


\section{Reconhecimento dos Estados de Ânimo pela Ciberarte}

Vygostki (2001b) questiona a relação da arte com a vida ou da reação estética com as reações do homem. A arte implica transformações. A arte nos contagia com certos sentimentos, induz a emoções e nos faz compreender realidades. $\mathrm{O}$ autor que escreveu suas teses nas primeiras décadas do século $\mathrm{XX}$, questionou as até então consagradas teorias que sustentavam as relações dicotômicas entre razão e emoção, cognição e afetividade, objetividade e subjetividade - dissociando a arte da ciência. Formulações como as de Vygostski somente conquistaram respaldo no plano da Neurociência e das Ciências Cognitivas a partir de importantes pesquisas realizadas nas duas últimas décadas (Damásio, 1996; Le Doux, 2005). De fato, vem sendo demonstrado que os "elementos dicotômicos" estão interligados entre si de forma complexa, constituindo papel fundamental em funções importantes do intelecto, dentre elas a tomada de decisão, a memorização e a criatividade.

Os fenômenos afetivos, tanto quanto os pensamentos, são expressos, voluntária ou involuntariamente, na forma de sons (palavras faladas, cantadas, cantaroladas ou deixas), de grafia (palavras escritas, desenhos, pinturas, etc.), de gestos (faciais, corporais), de comportamento (agitação, tranquilidade, rubor, etc.) e de outras formas criativas para exprimir a comunicação. A comunicação afetiva é captada por meio dos sentidos em ambiente real ou através de instrumentos mediadores (papel, telefone, vídeo, etc.). Pode ser visível ou subentendida. Em quaisquer dos casos, a comunicação afetiva é feita através de um padrão de informação que pode ser representado no computador. $\mathrm{O}$ reconhecimento dos estados afetivos passa a constituir um problema de reconhecimento de padrões (Picard, 1997).

O trabalho Empathic Painting demonstrado por Shugrina et alli (2006) torna evidente a possibilidade de construir mecanismos para o reconhecimento dos estados afetivos através das expressões faciais do sujeito, enquanto espectador da obra de arte. $\mathrm{O}$ projeto baseia-se nas teorias da Ciberarte quando o espectador modifica a obra em tempo real ao refletir seu estado de humor na arte digital. Após identificar o estado de humor do espectador, o sistema adapta a cor correspondente e as pinceladas na imagem digital. Na verdade, a arte muda para se adaptar ao humor do espectador. A estética não está mais no olho de quem aprecia a obra, está baseada no humor de quem olha a obra.

O Empathic Painting usa a tecnologia da visão computacional ${ }^{10}$ para detectar, em tempo real, a posição e a forma da boca, a abertura dos olhos, o sulco da testa e o ângulo de elevação ou retração das sobrancelhas para avaliar o estado afetivo do espectador. A obra digital muda de uma imagem escura e sombria para outra com cores vibrantes quando as expressões do observador vão de uma cara sisuda para uma em júbilo. São três os estados de humor que o Empathic Painting reconhece: desânimo, fúria e entusiamo. Shugrina et alli (2006) recorreram a estudos da psicologia (Russel, 2003; Ekman, 1999) para definir quais as cores e texturas se adaptam a cada estado de humor.

10 Visão computacional é a área da ciência da computação que se dedica a desenvolver teorias e métodos voltados à extração automática de informações úteis contidas em imagens ou quaisquer dados multi-dimensionais. As sub-áreas de pesquisa incluem a reconstrução de cena, detecção de eventos, reconhecimento de objetos, aprendizagem em máquina e restauração de imagens. 
Os resultados do trabalho de Shugrina et alli (2006) e os estudos desenvolvidos em estética digital e Ciberate promoveu a idéia de equipar a funcionalidade Planeta Arte com uma ferramenta que considere a afetividade nos projetos de artes desenvolvidos por alunos do Ensino Fundamental.

Assim, este estudo entende que, através da interdisciplinaridade (Educação, Artes, Informática e Ciências Cognitivas), é possível identificar os estados de ânimo analisando as cores utilizadas nos desenhos registrados no AVA Planeta ROODA permitindo ao professor escolher ações pedagógicas mais adequadas especialmente às que se referem ao suporte afetivo.

No trabalho proposto, após as crianças realizarem seus desenhos no Planeta Arte, o sistema identificará as cores e quantidade delas utilizadas. Estas servirão como parâmetros para inferir os estados de ânimo das crianças. A descrição e classificação dos estados de ânimo serão baseadas na teoria psicoevolucionária de Plutchick (2007) que define as emoções, suas intensidades e o estado de ânimo em um espaço geométrico tridimensional representado por um cone de cores (Figura 2).

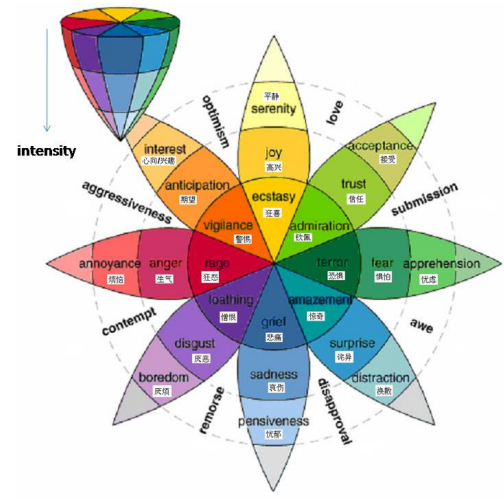

Figura 2: Espaço geométrico de descrição das emoções por Plutchick (Wang, 2007)

Para cada estado de ânimo, um conjunto de emoções está associado. O modelo dos estados de ânimo a ser utilizado neste trabalho (estar animado, estar desanimado e indiferente) é o apresentado por Scherer (2005) e as emoções categorizadas para o Planeta Arte podem ser vistas na Figura 3 e os estados de ânimo correspondentes na Tabela 1.

Os dados captados pelo sistema representam informações obtidas de modo vago (computacionalmente conhecidas por variáveis incertas). Desta forma, o modelo de Markov (HMM: Hidden Markov Model) é a opção computacional para tratar domínios com variáveis incertas. O HMM é um modelo estatístico bastante usado em sistemas que fazem reconhecimento de padrões de manuscritos coloridos ou não. Outros exemplos são o reconhecimento de padrões de voz, de gestos e de sons musicais.

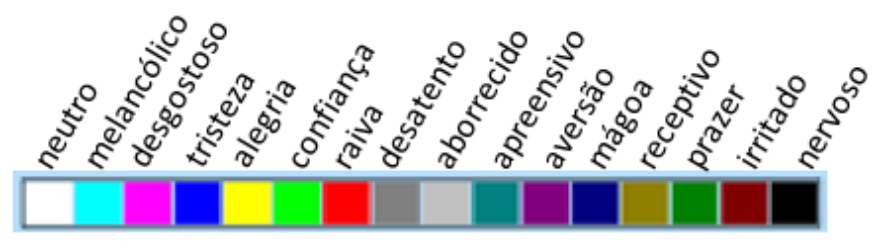

Figura 3: Categorização das cores para o editor Planeta Arte 


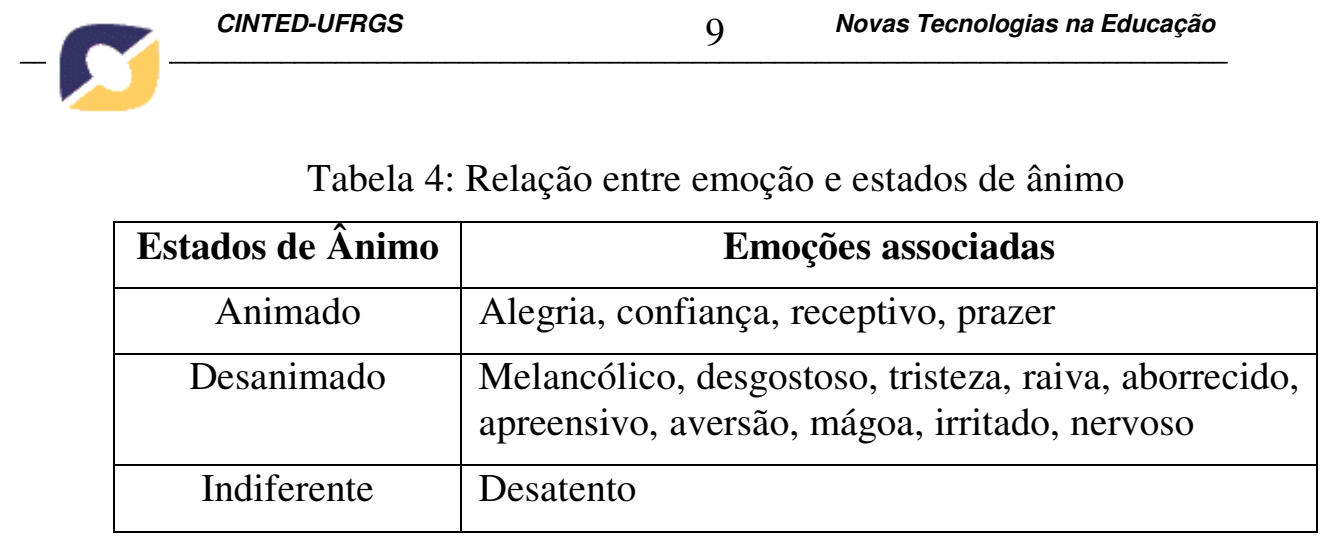

\section{Considerações Finais}

Este trabalho apresenta a importância de desenvolver uma ferramenta a ser acoplada ao Planeta Arte (funcionalidade do Planeta ROODA) e que faça inferências dos estados de ânimo a partir das cores utilizadas nos desenhos executados e registrados no ambiente. Atualmente, no presente estudo, estão sendo levantados os requisitos do sistema e analisadas as teorias psicológicas e os métodos computacionais adequados para aplicação.

Para tanto, é apresentado um método de reconhecimento dos estados de ânimo apartir da teoria de Plutchik, a qual associa os estados de ânimo às cores representadas em um espaço tridimencional e ao uso de modelo de Markov, através da linguagem artística registrada por crianças do Ensino Fundamental

Parte-se da necessidade de desenvolver ferramentas tecnológicas direcionadas a sistemas educacionais que tratam do reconhecimento de fenômenos afetivos. O desafio é desenvolver instrumentos que, partindo do reconhecimento dos estados afetivos do aluno, permitam ao professor uma percepção mais acurada a respeito de sua motivação.

É importante considerar que as tecnologias digitais, com suas novas formas de representação, exigem a reformulação dos conceitos estéticos. "O computador é apenas um meio de representação, o mais universal que o homem elaborou. O que é novo é o grau de integralidade da representação que ele permite atingir e o uso que dele podemos fazer". (Cadoz, 1997; p.9). Hoje se pensa em sistemas híbridos, onde a tecnologia é inserida não só para quebrar limites de espaço e tempo, mas para criar extensões do corpo e dos sentidos humanos.

Esta abordagem mostrou-se necessária como um primeiro estudo, dentro desta área interdisciplinar, destacando a necessidade de integrar teorias relacionadas à Ciberarte e à Endoestética, às tecnologias digitais.

\section{Referências Bibliográficas}

Behar, P. A.; Walquil, M.; Bernardi, M; Moresco, S. Refletindo sobre uma metodologia de pesquisa para AVA's. In: Congresso Internacional de Qualidade de Educação a Distância, 2005, São Leopoldo. Anais. São Leopoldo: Unisinos, v. 1. 2005.

Behar, P.A.; Leite, S.M.; Schneider, D.; Amaral, C.B. (2006). Educação Infantil e Ensino Fundamental: outras possibilidades através do PLANETA ROODA. Revista RENOTE, V. $4 \mathrm{~N}^{\mathrm{o}}$ 1, Julho.

Bercht, M.. Em Direção a Agentes Pedagógicos com Dimensões Afetivas. Instituto de Informática. UFRGS. Tese de Doutorado. 2001. 
Biazus, M. C. V. (2000). A Imagem digital e o sujeito cognitivo-criativo. Informática na Educação -Teoria Prática PGIE UFRGS, Porto Alegre, RS, v. 3.

Cadoz, C. (1997). Realidade Virtual. Tradução: Paulo Goya. São Paulo: Editora Ática.

Cordeiro, W. (1993). Arteônica. In: Mascarenhas, N., Velho, L. e Hess, L (orgs.) Cátalogo de Exposição. Recife. Diponível em (acessado em 27/11/2007) http://www.visgraf.impa.br/Gallery/waldemar/waldemar.htm.

Damásio, A. O Erro de Descartes: emoção, razão e o cérebro humano. Tradução: Dora Vicente e Georgina Segurado. São Paulo: Cia das Letras, 1996.

Domingues, D. (2004). Ciberespaço e rituais: tecnologia, antropologia e criatividade. Horizontes Antropológicos, v. 10, n. 21.

Ekman, P. (1999). Basic Emotions In: T. Dalgleish and T. Power (Eds.) The Handbook of Cognition and Emotion. p. 45-60. Sussex, U.K.: John Wiley \& Sons, Ltd. 1999.

Freire, P e Shor, I. (1987). Medo e Ousadia - o cotidiano do professor. São Paulo: Editora Paz e Terra.

Giannetti, C. (2006). Estética Digital: Sintopia da arte, ciência e a tecnologia. Tradução: Matia Angélica Melendi. Belo Horizonte: C/Arte.

Izard, C.E.. Basic emotions, relations among emotions, and emotion-cognition relations. In: Psychology Review. 99:561-65. 1992.

Le Doux, J. Emotion: Clues from the Brain. In: Annual Review Psychology. 46:209235, 1995.

Lemos, A. (2007). Ciberespaço e Tecnologias Móveis: processos de Territorialização e Desterritorialização na Cibercultura. in Médola, Ana Silvia; Araújo, Denise; Bruno, Fernanda. (orgs), Imagem, Visibilidade e Cultura Midiática, Porto Alegre, Editora Sulina, 2007., pp. 277-293., ISBN: 978-85-205-0464-2.

Lemos, A. (2003). Cibercultura. Alguns Pontos para compreender a nossa época. In: Lemos, A.; Cunha, P. (orgs). Olhares sobre a Cibercultura., Sulina, Porto Alegre, 2003; pp. 11-23.

Lemos, A. (1997). Anjos Interativos e Retribalização do Mundo. Sobre Interatividade e Interfaces Digitais. In: Tendências XXI, Lisboa, Portugal.

Lemos, A. (1996). Estruturas Antropológicas do Ciberespaço. In, Textos de Cultura e Comunicação, n. 35, Facom/Ufba, Salvador.

Lévy, P. (1999). Cibercultura. São Paulo: Editora 34.

Lévy, P. (1997). O que é o virtual. São Paulo: Editora 34.

Lévy, P. (2000). A emergência do Cyberspace e as mutações culturais. In: Ciberespaço: um hipertexto com Pierre Lévy. Pellanda, N.M.C \& Pellanda, E.C. (org.). Porto Alegre;Artes e Ofícios, 250p.

Mcluhan, H. M. (1974). Os meios de comunicação como extensões do homem. 4. ed. São Paulo: Cultrix, 407p.

Ortony, A, Clore, G., \& Collins. A. The cognitive structure os emotions. Cambridge: Cambridge University Press, 1988.

Outhwaite, W. \& Bottomore, T. (1996). Dicionário do pensamento social do século XX. Rio de Jeneiro: Jorge Zahae Ed..

Picard, R. W. Affective Computing. Cambridge: MIT Press. 1997. 
Piaget, J. The relation of affetivity to intelligence in the mental development of the child. In: Bulletin of the Menninger clinic. vol. 26, no 3. 1962.

Primo, A. (2003). Quão interativo é o hipertexto? : Da interface potencial à escrita coletiva. Fronteiras: Estudos Midiáticos, São Leopoldo, v. 5, n. 2, p. 125-142.

Plutchick, R. (2007). An overview of Plutchik's Theory of Emotions. Disponível em http://library.thinkquest.org/25500/index2.htm . Acessado em 13/11/2007.

Roseman, I.J., Jose, P., \& Spindel, M.S. Appraisals of emotion-eliciting events: Testing a theory of discrete emotions. Journal Personality and Social Psychology, 5(59), 899-915. 1990.

Russell, J.A. (2003). Core affect and the psychological construction of emotion. Psychological Review 110, 1, 145-172.

Scherer, K. What are emotions? And how can they be measured? In: Social Science Information 44 (4), 695-729. 2005.

Vygostki, L.S. (2001a) Obras Escogidas: Problemas de Psicología General. Madrid: A. Machado Libros. V. 2.

Vigotski, L.S. (2001b) Psicologia da arte. Tradução: Paulo Bezerra. São Paulo: Martins Fontes.

Wallon, H. As origens do caráter na criança: os prelúdios do sentimento de personalidade. São Paulo: Difusão Européia do Livro. 1971.

Wang, Z. (2007). Artificial Psychology. In: M.J. Smith, G. Salvendy (Eds.): Human Interface, Part I, HCII 2007, LNCS 4557, pp. 208 - 217. 